\title{
The Stability Study of a Novel Phenylpiperazine Derivative
}

\author{
Monika TARSA ${ }^{1}$, Małgorzata STAREK ${ }^{2 *}$, Monika DĄBROWSKA², Marzena BARAN ${ }^{1}$, Agnieszka \\ CZARNY $^{3}$, Marek CEGŁA ${ }^{1}$ \\ ${ }^{1}$ Department of Organic Chemistry, \\ ${ }^{2}$ Department of Inorganic and Analytical Chemistry, Faculty of Pharmacy, Jagiellonian University Medical College, \\ 9 Medyczna St, 30-688 Krakow, Poland, \\ ${ }^{3}$ Department of Organic Chemistry, Faculty of Chemistry, Jagiellonian University Medical College, 3 Ingardena St, \\ 30-060 Krakow, Poland \\ *E-mail: m.starek@uj.edu.pl
}

\begin{abstract}
N-phenylpiperazine compounds are a very large class of chemicals, and some of them have the ability to cross the blood-brain barrier due to the small size and the lipohilic nature. This group of compounds shows an interesting spectrum of biological activities. The chemical stability of the drugs determines the quality of the drug, affects safety, efficacy and storage conditions. The active compounds have diverse molecular structure and are susceptible to many variable degradation pathways, such as hydrolysis, oxidation, photodegradation, isomerization, elimination, dehydration and interaction with others substances. A hydrolysis degradation process is one of the most common destructive processes for chemical structures. It depends on various conditions e.g. temperature, $\mathrm{pH}$ and the chemical properties of a substance. The aims of this investigation were to study the stability testing of 2-[(4-phenylpiperazino)methyl]-2,3-dihydro-5H-[1,3]oxazolo[3,2-a]pyridine-5-one, a new oxazolopyridonyl derivative of phenylpiperazine. A probable pathway of its chemical degradation was designated, based on the kinetic parameters and the identification products by the chromatographic methods.
\end{abstract}

Keywords: N-phenylpiperazine; stability; spectrophotometry; chromatography

\section{Introduction}

Arylopiperazine potential structure is a very popular chemical class present in many biologically active compounds including drugs of therapeutic implication and compounds under countless stages of pharmacological screening. The aromatic area in combination with positive ionizable nitrogen of piperazine meets the structural requirements of binding pockets found in various protein targets that play important physiological roles in mammal tissues.

$\mathrm{N}$-phenylpiperazine compound constitute a very large class of chemicals and some of them have the ability to cross the blood-brain barrier due to the small size and the lipophilic nature of their molecules. Thus, some N- phenylpiperazine derivatives promote activity upon the central nervous system and are used in the treatment of various mental disorders, including anxiety, Alzheimer's, and depression [1,2]. Besides, a lot of compounds with N-phenylpiperazine moiety are widely used as clinical drugs for fighting diseases related to the cardiovascular system [3]. This group of the derivatives has exhibited useful applications as anthelmintics, as tuberculostatic compounds, and as antimotion sickness compounds [4-7]. As demonstrated, this compound shows an interesting spectrum of biological activities, and is a very active research field. Activity of phenylpiperazine derivatives depends mostly on the interaction with G-protein coupled receptors including adenosine, adrenergic, serotoninergic and dopaminergic receptors [8-11]. The classical examples of known phenylpiperazine derivatives are urapidil, naftopidil, BMY-7378, WAY-100635 and trazodone (Figure 1). The two first compounds are antihypertensive drugs [12,13], BMY-7378 and WAY-100635 are used in various pharmacological assays as potent $\alpha_{1}$-adrenoceptor antagonists [11,14], while trazodone is an antidepressant [1]. Recently, our team and other researchers have synthesized numerous promising compounds containing Nphenylpiperazine moiety $[4,9,11,15-19]$. 


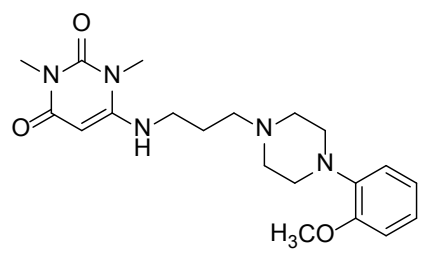

Urapidil

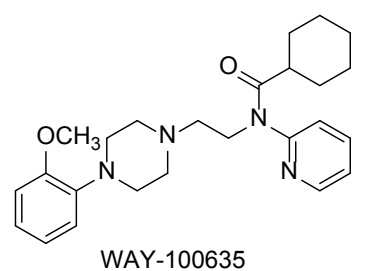

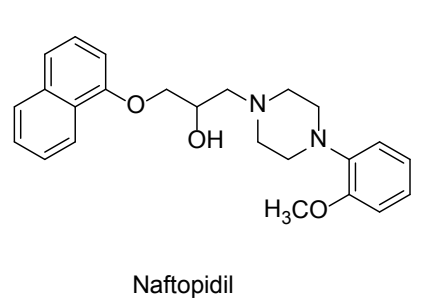

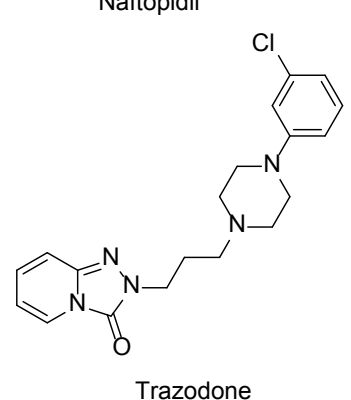<smiles>O=C1CC2(CCCC2)C(=O)N1CN1CCNCC1</smiles><smiles>COc1ccccc1C</smiles>

BMY-7378

Figure 1. An examples of the active phenylpiperazine derivatives.

The stability of new active compounds is as important as their biological activity, toxicity and pharmacokinetic properties [20-23]. The chemical stability is significant because it determines the quality of the drug, affects safety, efficacy and storage conditions. Knowledge of the drug's stability, especially at the $\mathrm{pH}$ in the range of 1-2, helps to design of potentially acid-labile drugs [24]. The active compounds have diverse molecular structure and are susceptible to many variable degradation pathways, such as hydrolysis, oxidation, photodegradation, isomerization, racemization, elimination, dehydration and interaction with others substances [21-26]. The most common consequence of the drug's degradation is the loss of potency, and in some cases, transformation to highly reactive chemical species which can cause tissue damage.

This knowledge would be useful if we could predict the chemical instability of a drug based on its structure. Aiming to obtain more efficient drugs containing N-phenylpiperazine moiety 2-[(4phenylpiperazino)methyl]-2,3-dihydro-5H-[1,3]oxazolo[3,2-a]pyridine-5-one was designated and synthesized by the reaction of 6-bromo-2-pyridone with 1-(2,3-epoxypropyl)-4-phenylpiperazine [27]. Therefore, in parallel with the ongoing biological testing, the stability of the candidate of novel series of potential $\alpha$-adrenoceptors ligands was determined. From the chemical point of view, the studied compound is oxazolopyridonyl derivative of phenylpiperazine (Figure 2). The synthesis, affinity to adrenoceptors and some physicochemical properties were described previously [19] but no report has been published on a possible catalytic hydrolysis in basic or acidic media.

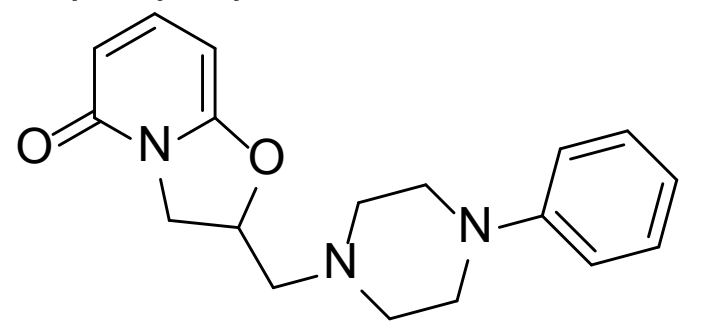

Figure 2. Structure of the new studied Compound Z.

This aspect of the research is very important especially in the case of novel compounds exhibiting biological activity. Assumption of stability testing is, next to active content determination, analysis of the changes in its concentration during storage and distribution with specific time and conditions. A hydrolysis degradation process is one of the most common destructive processes for chemical structures. It depends on various conditions e.g. temperature, $\mathrm{pH}$ and the chemical properties of a substance. The performed analysis of the hydrolytic degradation of the compound, over a wide range of $\mathrm{pH}$, may 
indicate a possible its degradation pathways.

The aim of the present study was to report our research of the stability testing of novel oxazolopyridonyl derivative of phenylpiperazine (compound $\mathbf{Z}$ ) having two different heteroatomic systems (a pyridone and a piperazine ring), one phenyl ring at the piperazine, and the cyclic heteroatomic ring of oxazol linked to the pirydon, going a 2-[(4-phenylpiperazino)methyl]-2,3-dihydro$5 \mathrm{H}-[1,3]$ oxazolo[3,2-a]pyridine-5-one. The newly synthesized compound was tested in aqueous solutions as a function of $\mathrm{pH}$ and temperature. A probable pathway of its chemical degradation was also investigated, based on the kinetic parameters and the identification products by HPLC-MS/MS technique.

\section{Experimental}

\subsection{Chemicals and Reagents}

The reaction of the synthesis of the compound $\mathbf{Z}$, named 2-[(4-phenylpiperazino)methyl]-2,3-dihydro-5H$[1,3]$ oxazolo[3,2-a]pyridine-5-one is illustrated in Figure 3 . This final product was obtained in the reaction of 6-bromo-2-pyridone, 1-(2,3-epoxypropyl)-4-phenylpiperazine and pyridine in anhydrous ethanol. After concentrating of obtained product (compound $\mathbf{Z}$ ) was crystallized from n-heptane : toluene $(3: 1, v / v)$. The structural elucidation of this compound was done via spectroscopic techniques, such as FT-IR spectroscopy, ${ }^{1} \mathrm{HNMR},{ }^{13} \mathrm{CNMR}$ and MS analysis, which was performed in Nuclear Magnetic Resonance Laboratory of Jagiellonian University Collegium Medicum (on apparatus: VarianMercury-VX300 MHz, USA). The signals were patterned on the signal of solvent $\mathrm{CDCl}_{3}$. The purity of the synthesized compound was checked by measuring the melting point, and using chromatographic retention parameters (recorded on TLC silica gel $60 \mathrm{~F}_{254}$ Merck plates as stationary phase, and chloroform : methanol $(9: 1, v / v)$, n-hexane : ethanol : triethylamine $(7: 1: 1, v / v / v)$ and chloroform : nhexane : triethylamine $(7: 1: 1, v / v / v)$ as mobile phases). Before starting the analyzes covered by the study plan, a spectral analysis of the obtained compound $\mathrm{Z}$ was also carried out, the results of which were compared with the data described in the paper [27].

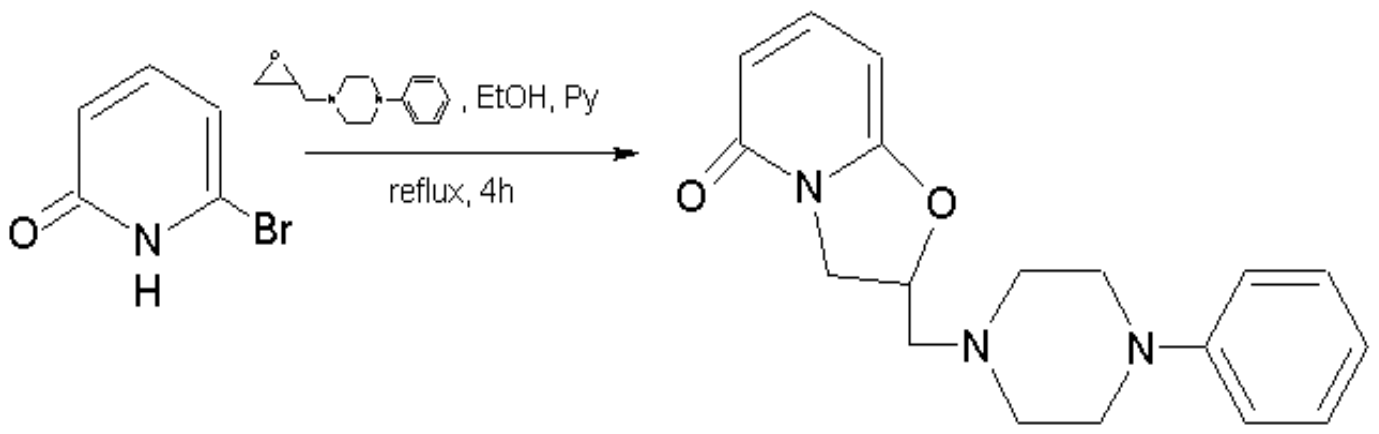

Figure 3. Reaction of the synthesis of the compound 2-[(4-fenylopiperazyn-1-yl)-2,3-dihydro-5H-[1,3] oksazolo[3,2a]pirydyn-5-on (compound $\mathbf{Z}$ ).

Acetonitrile, formic acid ethanol, chloroform, methanol, n-hexane and triethylamine of analytical grade were purchased from Merck (Darmstadt, Germany). The reagents $\mathrm{KH}_{2} \mathrm{PO}_{4}, \mathrm{HCl}, \mathrm{NaOH}, \mathrm{Na}_{2} \mathrm{~B}_{4} \mathrm{O}_{7} \cdot 10$ $\mathrm{H}_{2} \mathrm{O}$ and reference buffers of $\mathrm{pH} 4.7$ and 10.0 were purchased from Chempur (Piekary Śląskie, Poland). The other buffer solutions were made in accordance with the procedure available in the Physicochemical Guidance [28]. Stock solutions were prepared by dissolving a compound Z in ethanol.

\subsection{HPLC-MS/MS Analysis}

Liquid chromatography was performed using an Agilent 1100 (Agilent Technologies, Waldbronn, Germany) LC system with DAD detector G1315B. Chromatographic separation was carried out with an XTerra analytical column $\left(30 \times 2.1 \mathrm{~mm}, 3.5 \mu \mathrm{m}\right.$, Waters, Ireland) set at $30^{\circ} \mathrm{C}$. Solvent mixture of water: 
acetonitrile $(1: 1, v / v)$ with $10 \mathrm{~mL} \mathrm{~L}^{-1}$ of formic acid was used. The flow rate was set at $600 \mu \mathrm{L} \mathrm{min}{ }^{-1}$. A sample volume of $20 \mu \mathrm{L}$ was injected into the analytical column for compound analysis. Mass spectrometric analyses were accomplished on an Applied Biosystems MDS Sciex (Concord, Ontario, Canada) API2000 triple quadrupole mass spectrometer equipped with an electrospray ionization interface and performed in the positive ionization mode.

A standard solution of polypropylene glycols was used for instrument tuning and mass calibration at unit mass resolution according to the Applied Biosystems manual. The mass spectrometer was operated with a dwell time of $200 \mathrm{~ms}$, and a $5 \mathrm{~ms}$ delay between scans for each transition on the first quadrupole (Q1) in a range of 50 to $1000 \mathrm{Da}$. To find the optimal parameters of ion path and ion source of studied compound the quantitative optimization was done by direct infusion of reference solution at concentration of $0.001 \mathrm{M}$ at a flow rate of $10 \mu \mathrm{L} \mathrm{min}{ }^{-1}$ using a Hamilton syringe pump (Hamilton, Reno, Nevada). The ion source parameters were as follows: ion spray voltage (IS): $5500 \mathrm{~V}$; nebulizer gas (gas 1): 45 psi; turbo gas (gas 2): $45 \mathrm{psi}$; temperature of the heated nebulizer (TEM): $300^{\circ} \mathrm{C}$ and curtain gas (CUR): 10 psi. Nitrogen (99,9\%) from Peak NM20ZA was used as the curtain and collision gas. The ion path parameters were as follows: declustering potential (DP): 10V; focusing potential (FP): $350 \mathrm{~V}$; entrance potential (EP): 10V, electron multiplier (CEM): 2500V; collision cell entrance potential (CEP): $44 \mathrm{~V}$; and collision cell exit potential (CXP): 25V, respectively. Data acquisition and processing were accomplished using the Applied Biosystems Analyst ver.1.4.2 software.

\subsection{TLC Analysis}

The solutions were applied on TLC $60 \mathrm{~F}_{254}$ chromatographic plates $(13 \times 10 \mathrm{~cm}$, cut from $20 \times 20 \mathrm{~cm}$ plates; Merck, Germany) coated with $0.20 \mathrm{~mm}$ layers of silica gel. Samples volume of $10 \mu \mathrm{L}$ of the relevant solutions were spotted as bands $10 \mathrm{~mm}$ wide and $8 \mathrm{~mm}$ apart, first application $\mathrm{X}$ axis $10 \mathrm{~mm}$ and $\mathrm{Y}$ axis $5 \mathrm{~mm}$, by use of sample applicator Linomat V (Camag, Muttenz, Switzerland), equipped with a $100-\mu \mathrm{L}$ syringe with a constant application rate of $200 \mathrm{~nL} \mathrm{~s}{ }^{-1}$. Various mobile phases were tested. Plates were developed at room temperature in a glass vertical TLC chamber $(18 \times 9 \times 18 \mathrm{~cm}$ in size, Sigma-Aldrich), previously saturated with mobile phase vapor for 15 min. A distance of chromatogram run was $95 \mathrm{~mm}$. Next, the chromatograms were dried in a current of air at room temperature, and analyzed densitometrically within the range of 200 to $400 \mathrm{~nm}$. Densitometric scanning was performed with a TLC Scanner 3 with Cats 4 software (Camag, Muttenz, Switzerland) in reflectance/absorbance mode at $350 \mathrm{~nm}$. The slit dimensions were kept at $4 \times 0.45 \mathrm{~mm}$ and the scanning speed was $20 \mathrm{~mm} \mathrm{~s}^{-1}$.

\subsection{Statistical Analysis}

The obtained data are expressed as the mean values \pm SD (standard deviation) resulting from five measurements. Statistical analysis was performed with Statistica v10 (StatSoft, Poland).

\section{Results and Discussion}

First, the Lambert-Beer law compliance was checked. For this purpose a $0.001 \mathrm{M}$ solution of compound $\mathbf{Z}$ in ethanol (as stock solution) was prepared. It was diluted, and a series of working solutions at various concentrations in the range from $2 \cdot 10^{-5}$ to $8 \cdot 10^{-5} \mathrm{M}$ were prepared, and the absorbance was measured at wavelengths corresponding to the maxima (Figure 4). The obtained results are given in Table 1. Next, based on these results, the molar absorption coefficient values were calculated and the curves of an absorbance versus molar concentration were plotted (Figure 5). The obtained dependencies were linear which confirmed the reasonableness of the application of UV-Vis spectrophotometry for kinetics measurements. 


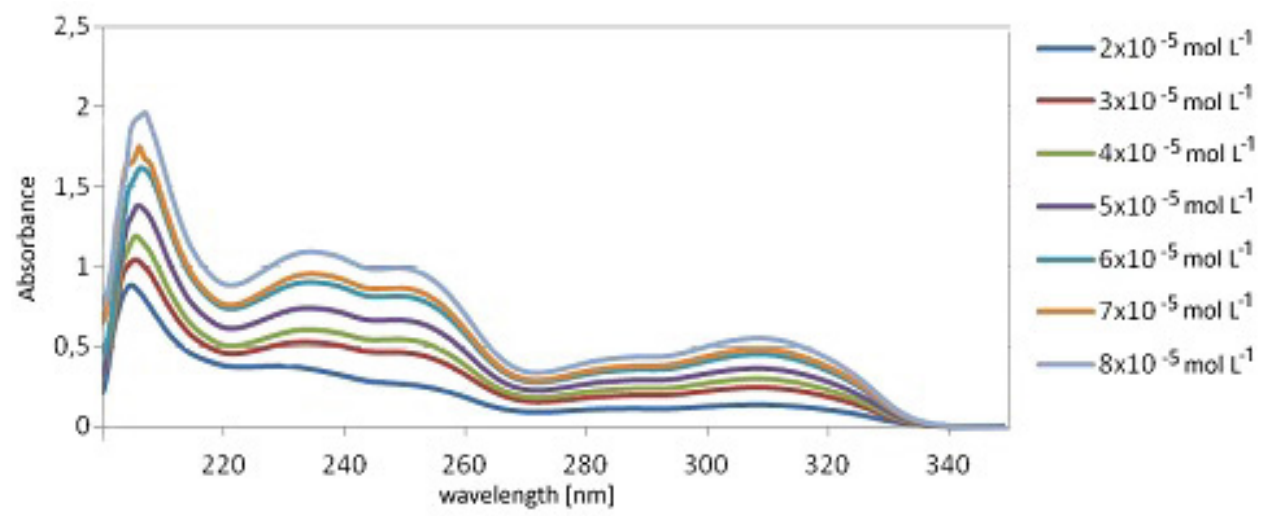

Figure 4. UV spectra recorded for ethanolic solutions of Compound $\mathbf{Z}$ in various concentrations.

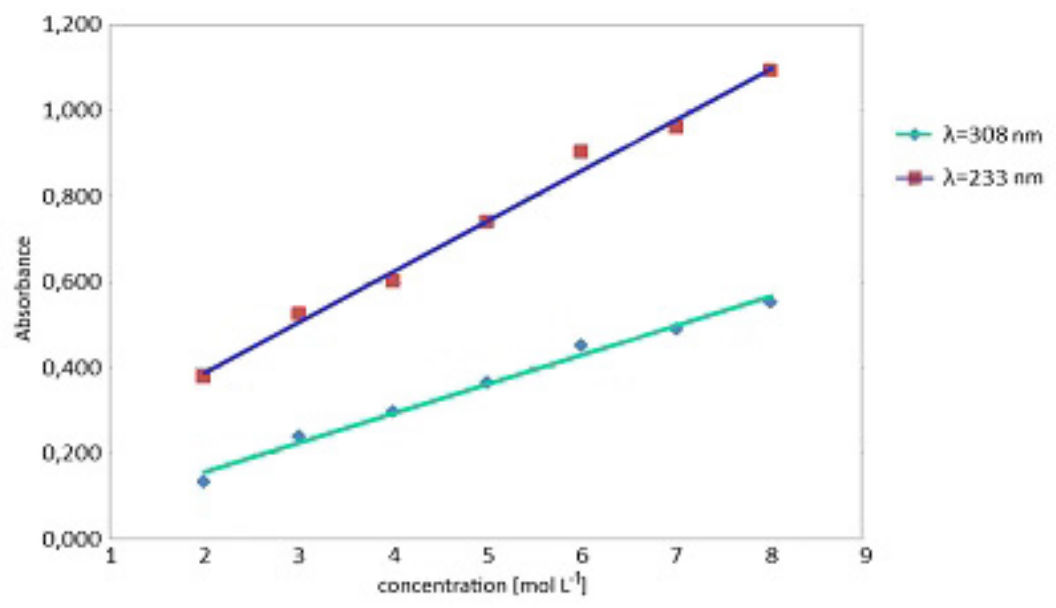

Figure 5. Correlation graphs of an absorbance versus molar concentration for the Compound $\mathrm{Z}(\mathrm{A}=\mathrm{f}(\mathrm{c}))$.

Table 1. Absorbance and molar absorption coefficients obtained for a series of ethanolic solutions of compound Z

\begin{tabular}{|c|c|c|c|c|}
\hline $\begin{array}{c}\text { Concentration } \\
{\left[\mathrm{x} 10^{-5}, \mathrm{M}\right]}\end{array}$ & $\begin{array}{l}\text { Absorbance } \\
\lambda=233 \mathrm{~nm}\end{array}$ & $\begin{array}{c}\text { Molar Absorption } \\
\text { Coefficient } \lambda=233 \mathrm{~nm}\end{array}$ & $\begin{array}{c}\text { Absorbance } \\
\lambda=308 \mathrm{~nm}\end{array}$ & $\begin{array}{c}\text { Molar Absorption } \\
\text { Coefficient } \lambda=308 \mathrm{~nm}\end{array}$ \\
\hline 2 & 0.133 & 6650.0 & 0.378 & 1890.0 \\
\hline 3 & 0.241 & 8033.3 & 0.525 & 1750.0 \\
\hline 4 & 0.296 & 7400.0 & 0.602 & 1505.0 \\
\hline 5 & 0.365 & 7300.0 & 0.740 & 1480.0 \\
\hline 6 & 0.452 & 7533.3 & 0.902 & 1503.3 \\
\hline 7 & 0.489 & 6985.7 & 0.960 & 1371.4 \\
\hline \multirow[t]{2}{*}{8} & 0.553 & 6662.5 & 1.092 & 1365.0 \\
\hline & Mean Value & 7223.5 & Mean Value & 1552.1 \\
\hline
\end{tabular}

In the next part of our study, the changes of absorbance over time, recorded for a $6 \cdot 10^{-5} \mathrm{M}$ solution of compound $\mathbf{Z}$ in pH 1.09 and 10.0 buffers were analyzed (Figures 6,7). Similarly, measurements at various $\mathrm{pH}$ values from 1.0 to 12.0 were conducted, and relationship of $\mathrm{A}_{\max }$ values versus time was plotted. Then, for the obtained results a logarithmic plot, $\log \left(\mathrm{A}_{\max }\right)=f(\mathrm{t})$, was designated (Figure 8). 


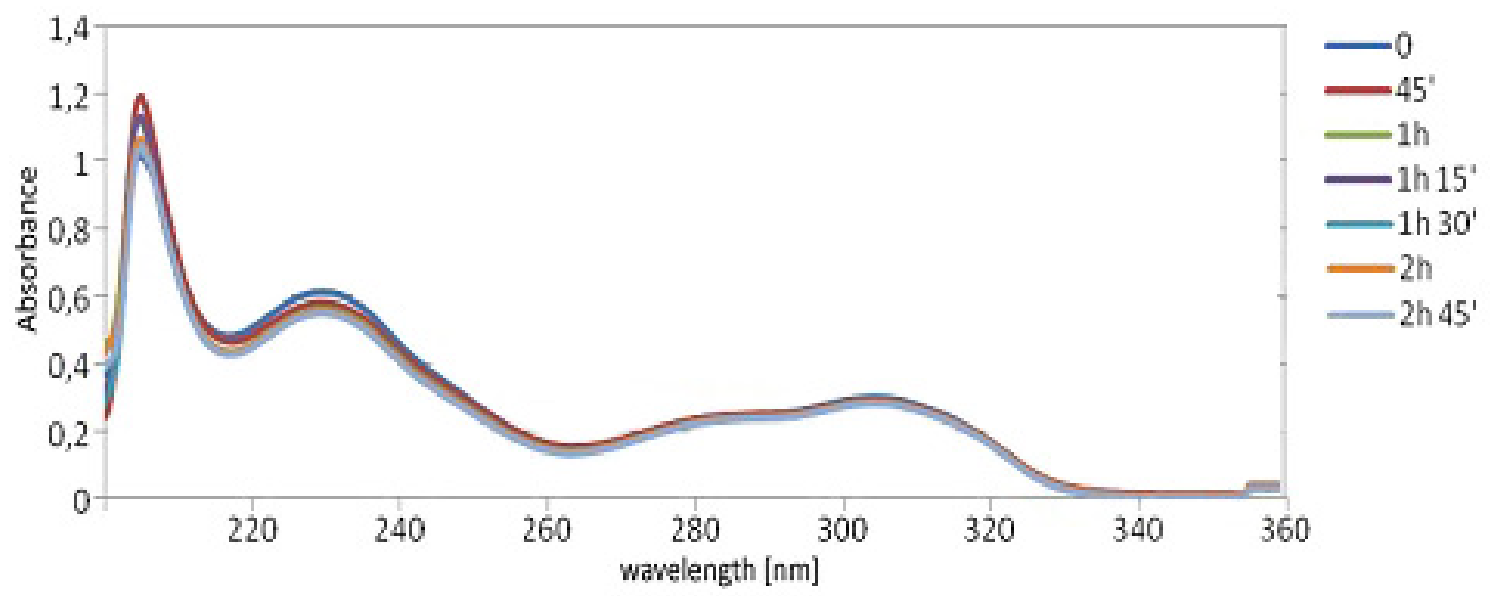

Figure 6. Absorbance versus time; plots for solutions of Compound $\mathbf{Z}$ in buffer $\mathrm{pH} 1.09$ at $60^{\circ} \mathrm{C}$.

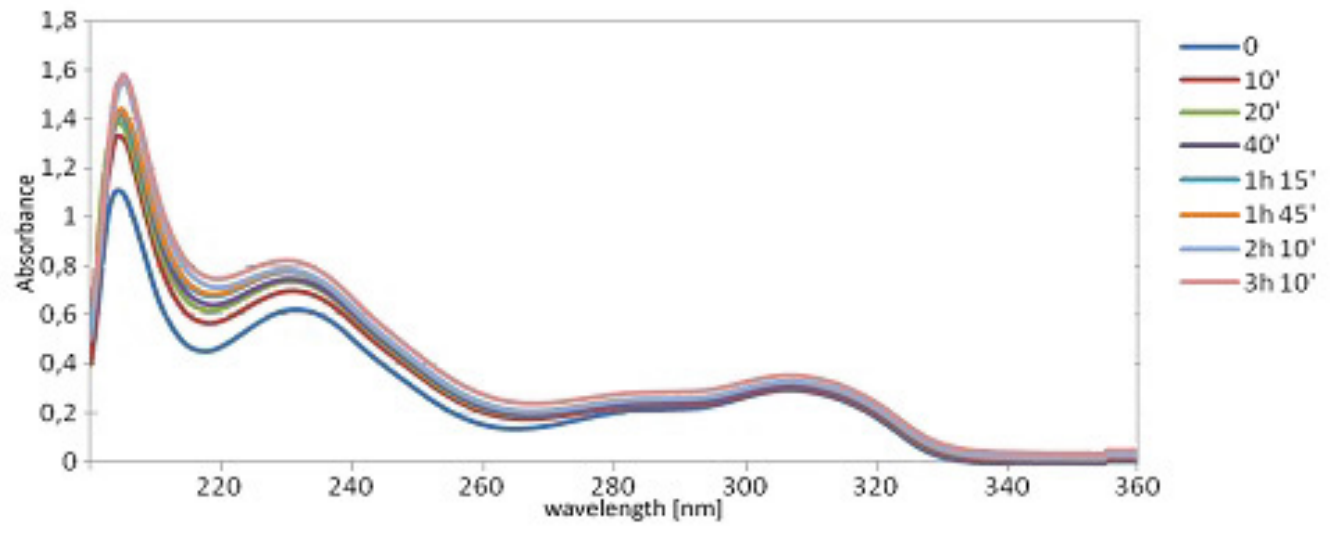

Figure 7. Absorbance chances in $\mathrm{pH} 10.00$ solutions at temperature $60^{\circ} \mathrm{C}$.
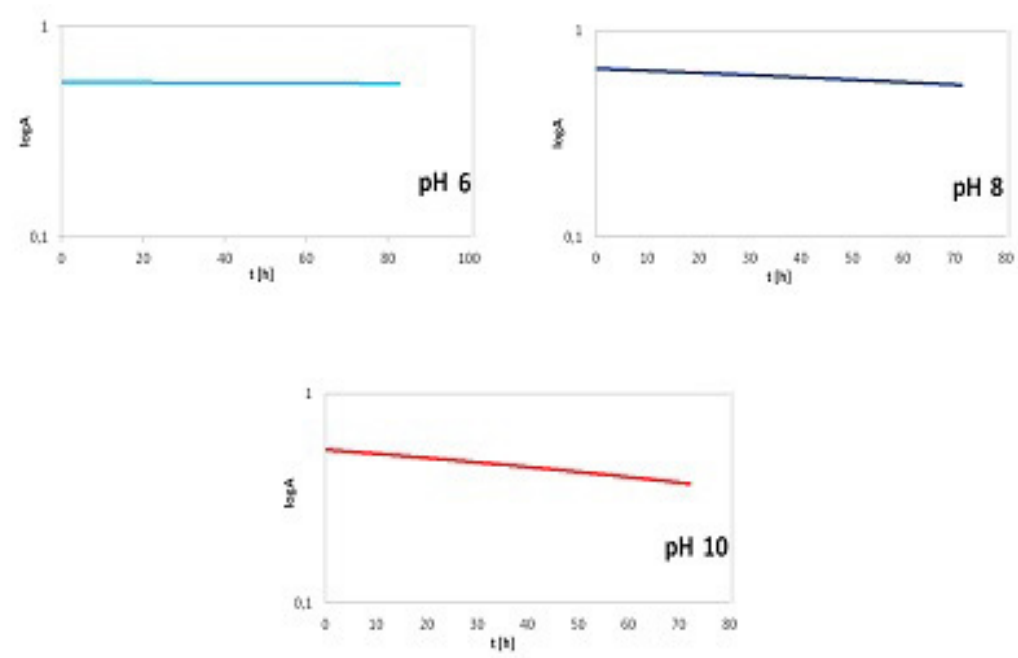

Figure 8. A logarithmic plots $\left(\log \left(\mathrm{A}_{\max }\right)=f(\mathrm{t})\right)$ appointed at $60^{\circ} \mathrm{C}$ in buffers at various $\mathrm{pH}$.

All obtained dependencies were linear and they inducted that the reaction decomposition of 
compound $\mathrm{Z}$ proceeds according to the pseudo-first order kinetics.

From the correlation obtained for the $\mathrm{A}_{\max }=f(\mathrm{t})$, the rate constants were calculated, according to the $\mathrm{Eq}(1)$ :

$$
\log \left(\mathrm{A}-\mathrm{A}_{\infty}\right)=\log \left(\mathrm{A}_{0}-\mathrm{A}_{\infty}\right)-\mathrm{kt} / 2,303
$$

where: $A_{0}$ - the absorbance measured at the starting point $\left(t_{0}\right), A-$ the absorbance after $t$ hours, $A_{\infty}-$ the absorbance measured for the final point, $\mathrm{k}$ - the rate constant, $\mathrm{t}$ - the time.

Obtained results were collected in Table 2.

Table 2. The kinetic parameters calculated for compound $\mathrm{Z}$ in buffer solutions at different $\mathrm{pH}$, at temperature $60^{\circ} \mathrm{C}$

\begin{tabular}{cccc}
\hline $\mathrm{pH}$ & $\mathrm{k}\left[\times 10^{-5}, \mathrm{~s}^{-1}\right]$ & $\operatorname{logk}$ & $\mathrm{t}_{0.5}[\mathrm{~h}]$ \\
\hline 1.94 & 23.500 & -3.63 & 2948.94 \\
3.55 & 0.272 & -5.57 & 254779.41 \\
4.37 & 0.136 & -5.87 & 509558.82 \\
5.23 & 0.487 & -5.31 & 142299.79 \\
6.01 & 0.326 & -5.49 & 212576.69 \\
7.02 & 0.320 & -5.49 & 216562.50 \\
8.20 & 0.070 & -6.15 & 984375.00 \\
9.11 & 0.339 & -5.47 & 204424.78 \\
10.00 & 26.300 & -3.58 & 2634.98 \\
\hline
\end{tabular}

Note: $k$ - the reaction rate constant; $t_{0.5}$ - the time, concentration will decrease $50 \%$

The process of the hydrolysis in the range $\mathrm{pH}$ 2-10 occurs under pseudo-first order kinetics reaction. Present in the solution hydroxide $(\mathrm{pH}>9)$ and hydrogen $(\mathrm{pH}<3)$ ions accelerate degradation process, as illustrated by the graph (Figure 9$)$.

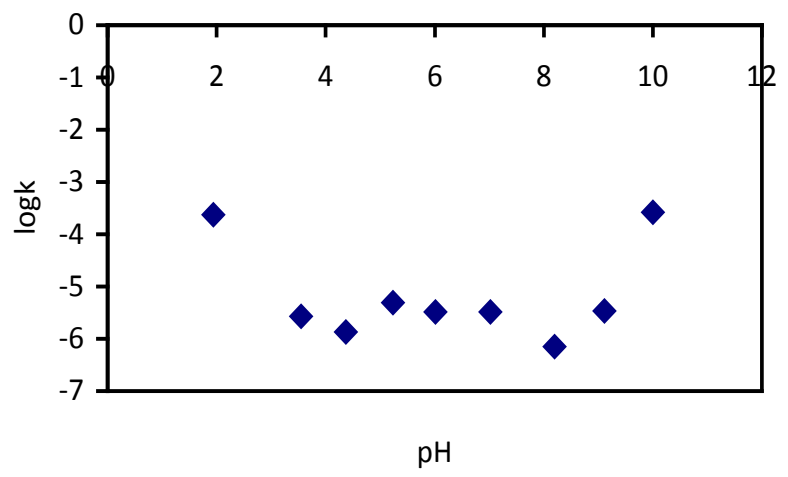

Figure 9. The dependency of the reaction rate constants on $\mathrm{pH}$.

A preliminary analysis of 2-[(4-phenylpiperazino)methyl]-2,3-dihydro-5H-[1,3] oxazolo[3,2-a]pyridine-5one decomposition process was carried out by thin layer chromatography. For this purpose, $1 \%$ solutions of the tested compound in $0.2 \mathrm{M} \mathrm{HCl}$ and ethanol $(4: 1, v / v)$ were prepared. Then, $0.5 \mathrm{~mL}$ of these solutions were transferred into the glass ampoules. Sealed ampoules were placed in an oven and heated at $120^{\circ} \mathrm{C}$ in a specified period of time (Figure 10). Next, $10 \mu \mathrm{L}$ were taken, and applied on the TLC plates using Hamilton's syringe (Hamilton Comp., USA). The reference substance solution prepared in ethanol was also applied. The plates were developed with various eluent systems. The best resolution was obtained using mobile phases consisted of: chloroform : methanol $(9: 1, v / v)$ and nheksane : ethanol : triethylamine $(7: 1: 1, v / v / v)$, which gave a good separation of registered spots with minimum tailing. In described conditions, symmetric and well-shaped peaks were received, derived both from degradation products and reference substance. For the plate visualization UV light at $254 \mathrm{~nm}$ was used. The observed changes are presented in Figure 10. 
a)
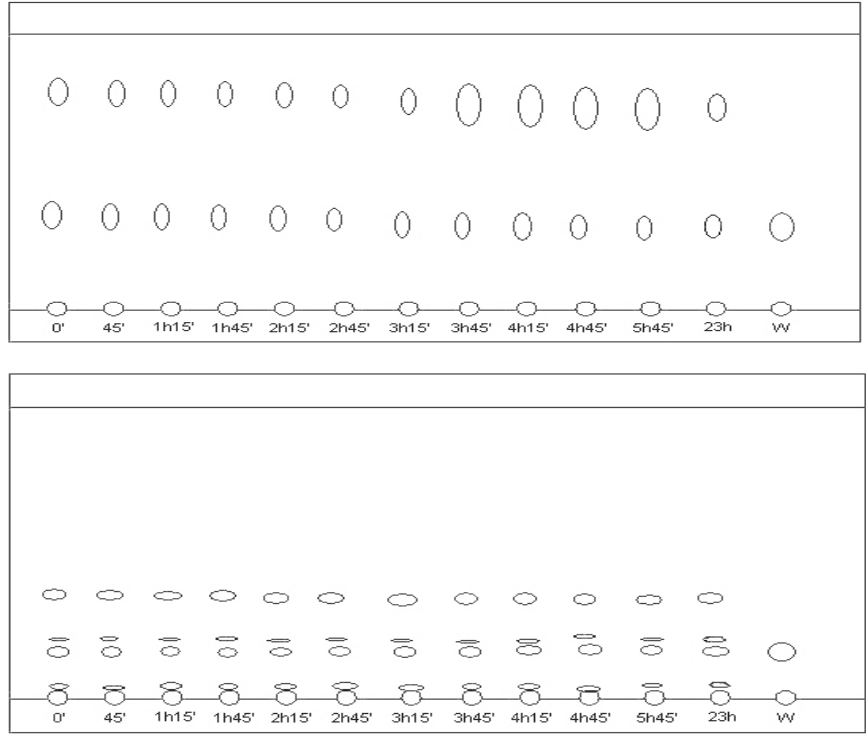

Figure 10. An example of the chromatograms obtained for the degradation process of the Compound $\mathbf{Z}$ using mixture chloroform : methanol $(9: 1, v / v)$ (a) and n-hexane : ethanol : triethyloamine $(9: 1, v / v)(\mathbf{b})$. Note: $w$ standard solution.

The chromatograms were analysed densitometrically at $254 \mathrm{~nm}$. Densitometric scanning was performed with a TLC Scanner 3 with Cats 4 software (Camag, Muttenz, Switzerland) in reflectance absorbance mode, slit with $6 \times 0.45 \mathrm{~mm}$, scanning speed $20 \mathrm{~mm} / \mathrm{s}$. An example of the registered densitograms is presented in Figures 11 and 12.

a)

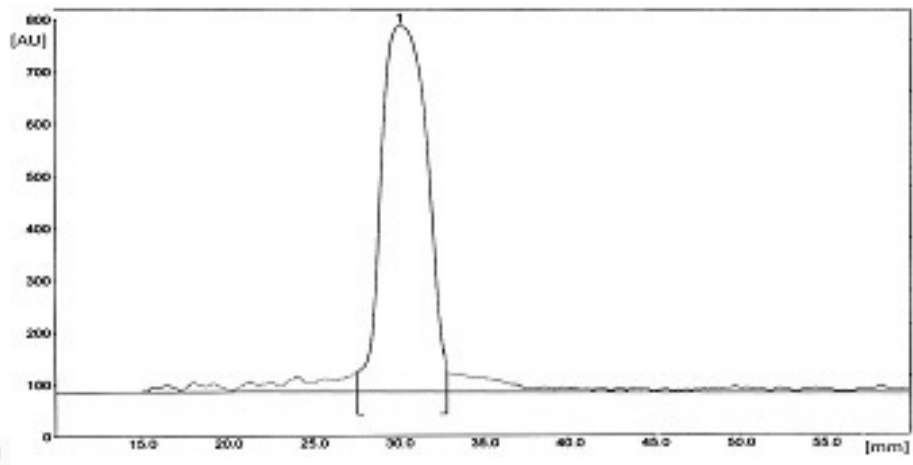

b)

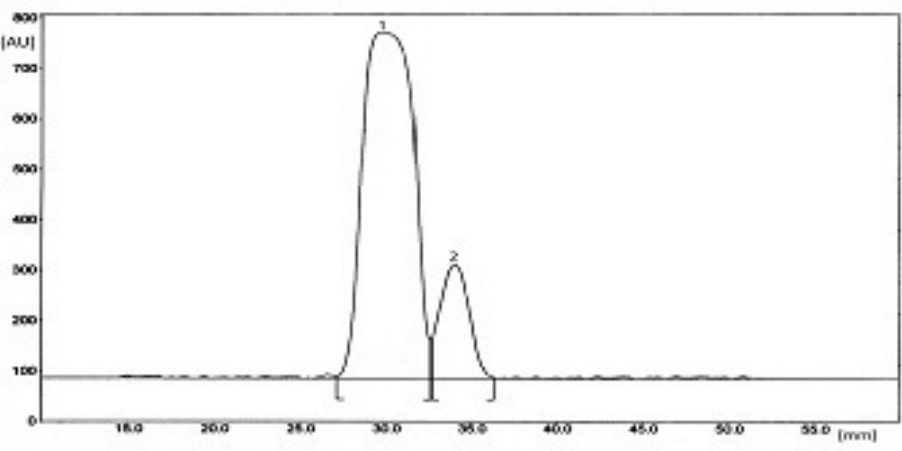

Figure 11. An example of densitogram in mobile phase consisted of chloroform : methanol $(9: 1, v / v)$; (a) standard solution of the of Compound $\mathbf{Z}$; (b) after $1 \mathrm{~h}$ incubation in $0.2 \mathrm{M} \mathrm{HCl}$ solution. 
a)

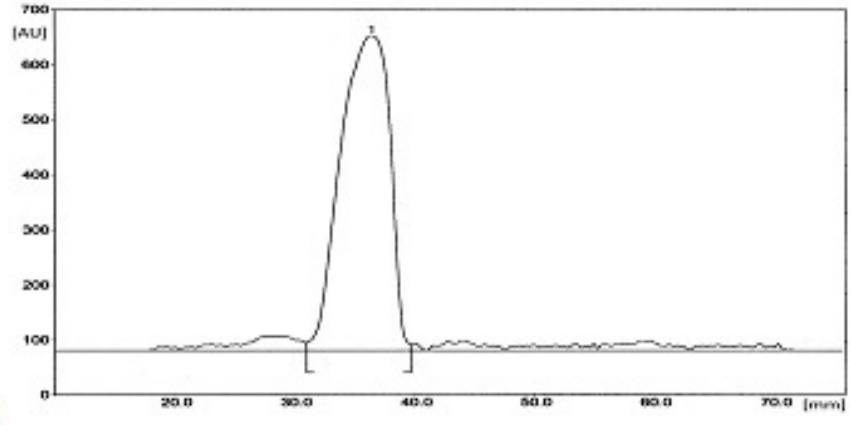

b)
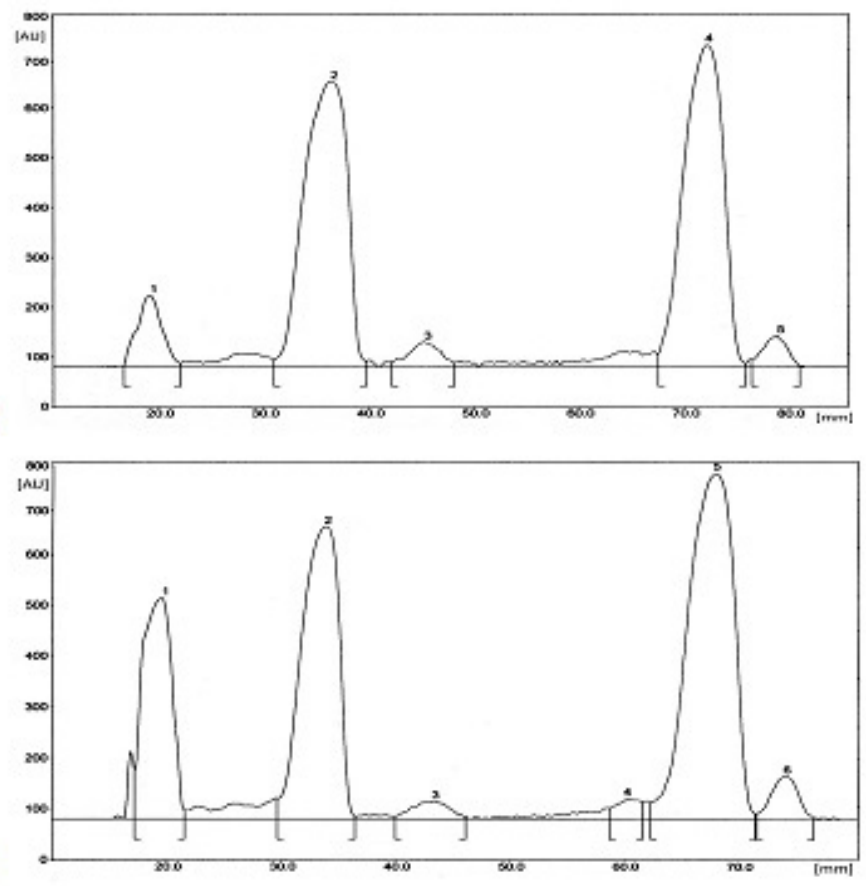

Figure 12. An example of densitogram in mobile phase consisted of n-heksane : ethanol : triethylamine (7:1:1, $\mathrm{v} / \mathrm{v} / \mathrm{v}$ ); (a) after $3 \mathrm{~h}$ incubation in $0.2 \mathrm{M} \mathrm{HCl}$; (b) after $3 \mathrm{~h}$ incubation in $0.2 \mathrm{M} \mathrm{HCl}$; (c) after $10 \mathrm{~h}$ incubation in $0.2 \mathrm{M} \mathrm{HCl}$.

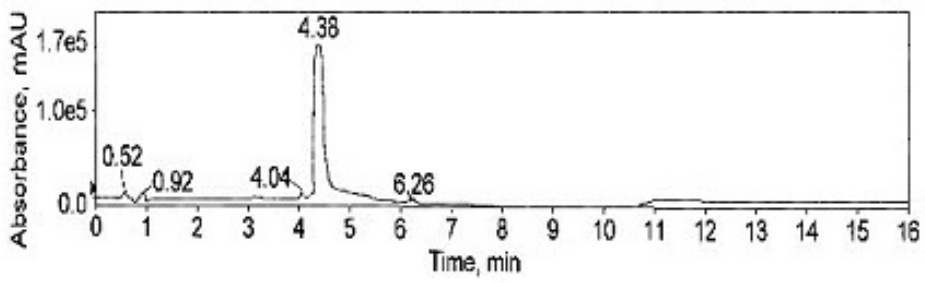

a)

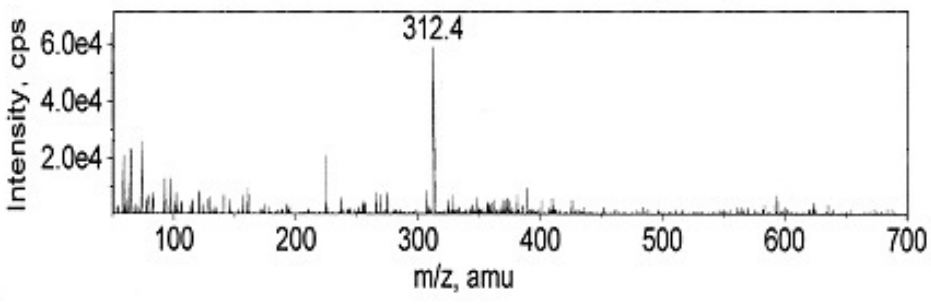

Figure 13. An example of the chromatogram (a) and MS spectrum (b) for the Compound $\mathbf{Z}$. 


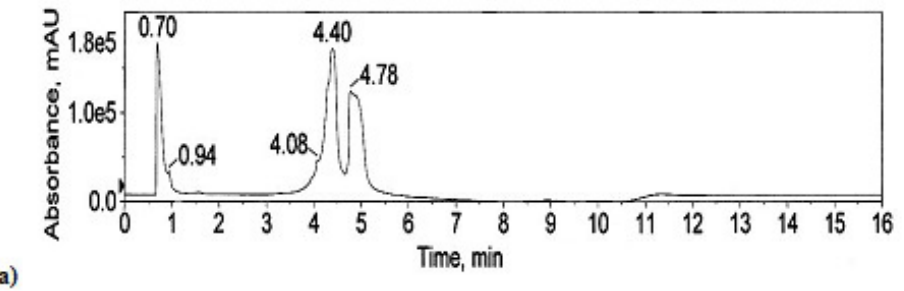

a)

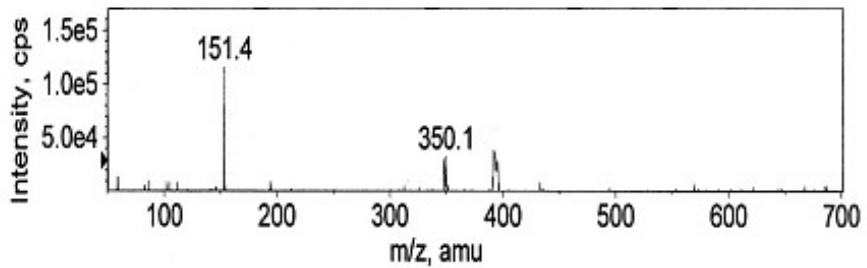

b)

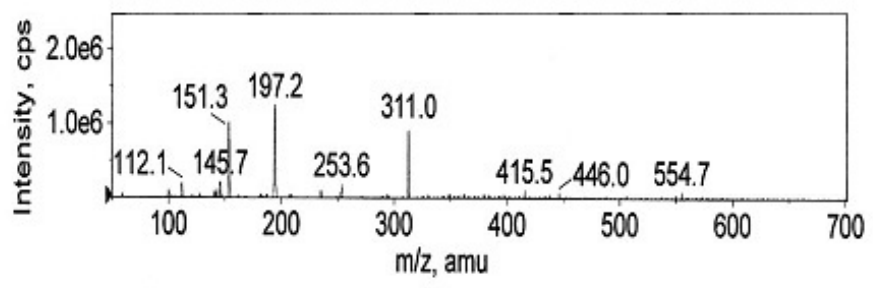

Figure 14. An example of the chromatogram for the degradation of compound $\mathbf{Z}$ after $3 \mathrm{~h}$ hydrolysis in $0.2 \mathrm{M} \mathrm{HCl}$ (a) and MS spectra: at $0.7 \mathrm{~min}(\mathbf{b})$; at $4.8 \mathrm{~min}(\mathbf{c})$.

Based on the achieved results, in the next part of our study, we undertook research to identify degradation products of 2-[(4-phenylpiperazino)methyl]-2,3-dihydro-5H-[1,3] oxazolo[3,2-a]pyridine-5-one using HPLC-MS/MS technique. The number of peaks registered on the chromatograms was comparable with those obtained by TLC analysis (Figures 13a, 14a).

In the mass spectra, among others, signals at $m / z 312,197$ and 151 were visible (Figures $13 \mathrm{~b}$ and $14 \mathrm{~b}, \mathrm{c})$. The recorded mass signal at $\mathrm{m} / z 312$ corresponds to 2-[(4-phenylpiperazino)methyl]-2,3-dihydro$5 \mathrm{H}$-[1,3] oxazolo[3,2-a]pyridine-5-one (compound $\mathbf{Z}$ ). Fragmentation of this structure leads to fragments at $m / z 151$ and 197 . The product at $m / z 151$ is 2-methyl-2,3-dihydro-5H-[1,3]oxazolo[3,2-a]pyridine-5one (compound A). The signal at $\mathrm{m} / z 197$ probably comes from 1-phenylpiperazine hydrochloride (compound B). A performed experiment allowed the probable pathway of the hydrolytic decomposition of compound $\mathbf{Z}$ which is showed in Figure 15.

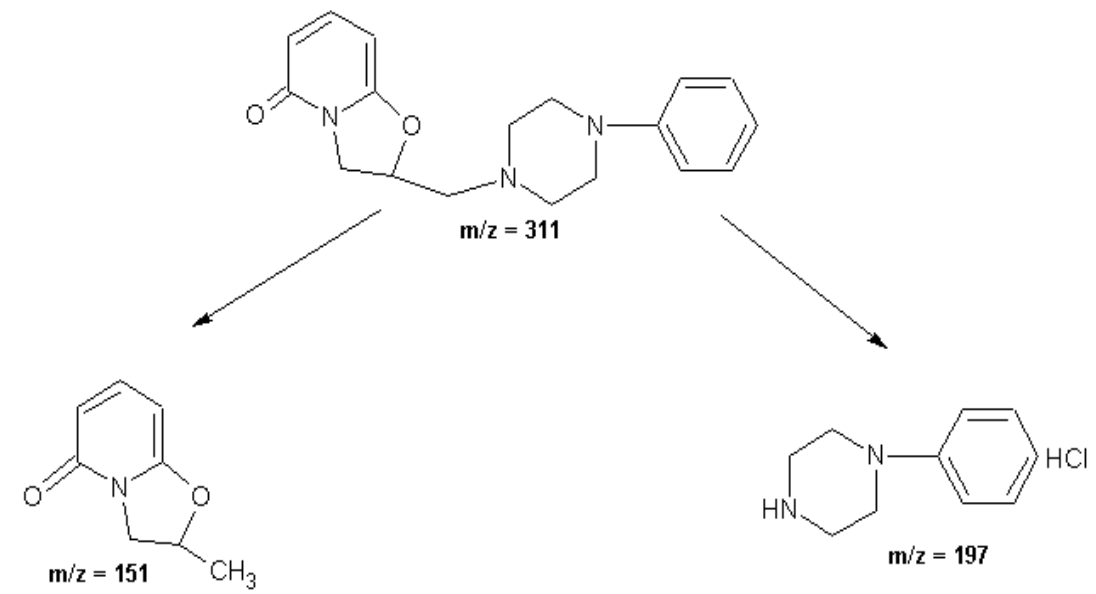

Figure 15. A probable pathway of the degradation of 2-[(4-phenylpiperazino)methyl]-2,3-dihydro-5H$[1,3]$ oxazolo[3,2-a]pyridine-5-one (Compound Z). 


\section{Conclusions}

A kinetic of the hydrolytic degradation of 2-[(4-phenylpiperazino)methyl]-2,3-dihydro-5H[1,3]oxazolo[3,2-a]pyridine-5-one (compound $\mathbf{Z}$ ) using spectrophotometric and chromatographic methods was studied. Obtained results show that this degradation process over a $\mathrm{pH}$ range 1-12 occurs according to pseudo-first order kinetic reaction. Hydroxide and hydrogen ions present in the solution accelerate this reaction. The results show that in stronger alkaline and acidic environment increases the speed of the reaction. The study allowed initially to determine the likely route of hydrolytic degradation of 2-[(4fenylopiperazyn-1-yl)-2,3-dihydro-5H-[1,3] oksazolo[3,2-a]pirydyn-5-one.

\section{References}

1. Fagiolini, A. Comandini, M. Catena Dell'Osso and S. Kasper, "Rediscovering trazodone for the treatment of major depressive disorder", CNS Drugs, vol. 26, pp. 1033-1049, 2012.

2. G. Neves, R. Fenner, A.P. Meckler, A.F. Viana, L. Tasso, R. Menegatti, C.A.H. Fraga, E.J. Barreiro, T. DallaCosta and S.M.K. Rates, "Dopaminergic profile of new heterocyclic N-phenylpiperazine derivatives", Braz. J. Med. Biol. Res., vol. 36, pp. 625-629, 2003.

3. K.S. Jain, J.B. Bariwal, M.K. Kathiravan, M.S. Phoujdar, R.S. Sahne, B.S. Chauhan, A.K. Shah and M.R. Yada, "Recent advances in selective alpha1-adrenoreceptor antagonists as antihypertensive agents", Bioorg. Med. Chem., vol. 16, pp. 4759-4800, 2008.

4. J. Handzlik, M. Bajda, M. Zygmunt, D. Maciąg, M. Dybała, M. Bednarski, B. Filipek, B. Malawska and K. Kieć-Kononowicz, "Antiarrhythmic properties of phenylpiperazine derivatives of phenytoin with $\alpha_{1}$-adrenoceptor affinities", Bioorg. Med. Chem., vol. 20, pp. 2290-2303, 2012.

5. Y.B. Lee, Y.D. Gong, D.J. Kim, C.H. Ahn, J.Y. Kong and N.S. Kang, "Synthesis, anticancer activity and pharmacokinetic analysis of 1-[(substituted 2-alkoxyquinoxalin-3-yl)aminocarbonyl]-4-(hetero)arylpiperazine derivatives", Bioorg. Med. Chem., vol. 20, pp. 1303-1309, 2012.

6. A. Blaser, B.D. Palmer, H.S. Sutherland, I. Kmentova, S.G. Franzblau, B. Wan, Y. Wang, Z. Ma, A.M. Thompson and W.A. Denny, "Structure-activity relationships for amide-, carbamate-, and urea-linked analogues of the tuberculosis drug (6S)-2-nitro-6-\{[4-(trifluoromethoxy)benzyl]oxy $\}-6,7$-dihydro-5H-imidazo[2,1b][1,3] oxazine (PA-824)", J. Med. Chem., vol. 55, pp. 312-326, 2012.

7. J. Handzlik, D. Maciąg, M. Kubacka, S. Mogilski, B. Filipek, K. Stadnicka and K. Kieć-Kononowicz, "Synthesis, $\alpha_{1}$-adrenoceptor antagonist activity, and SAR study of novel arylpiperazine derivatives of phenytoin", Bioorg. Med. Chem., vol. 16, pp. 5982-5998, 2008.

8. J. Handzlik, A.J. Bojarski, G. Satała, M. Kubacka, B. Sadek, A. Ashoor, A. Siwek, M. Więcek, K. Kucwaj, B. Filipek and K. Kieć-Kononowicz, "SAR-studies on the importance of aromatic ring topologies in search for selective $5-\mathrm{HT}_{7}$ receptor ligands among phenylpiperazine hydantoin derivatives", Eur. J. Med. Chem., vol. 78, pp. 324-339, 2014.

9. R. Romagnoli, P.G. Baraldi, M.D. Carrion, C.L. Cara, O. Cruz-Lopez, M.K. Salvador, D. Preti, M.A. Tabrizi, A.R. Moorman, F. Vincenzi, P.A. Borea and K. Varani, "Synthesis and Biological Evaluation of 2-Amino-3-(4chlorobenzoyl)-4-[(4-arylpiperazin-1-yl)methyl]-5-substituted-thiophenes. Effect of the 5-Modification on Allosteric Enhancer Activity at the A Adenosine Receptor", J. Med. Chem., vol. 55, pp. 7719-7735, 2012.

10. M. Leopoldo, E. Lacivita, F. Berardi, R. Perrone and P.B. Hedlund, "Serotonin 5-HT7 receptor agents: Structure-activity relationships and potential therapeutic applications in central nervous system disorders", Pharmacol. Ther., vol. 129, pp. 120-148, 2011.

11. G. Romeo, L. Materia, G. Marucci, M. Modica, M. Pittalá, L. Salerno, M.A. Siracusa, M. Buccioni, P. Angeli and K.P. Minneman, "New pyrimido[5,4- $b]$ indoles and [1] benzothieno[3,2- $d]$ pyrimidines: High affinity ligands for the $\alpha_{1}$-adrenoceptor subtypes", Bioorg. Med. Chem. Lett., vol. 16, pp. 6200-6203, 2006.

12. J. Buch, "Urapidil, a dual-acting antihypertensive agent: Current usage considerations", Adv. Ther., vol. 27, pp. 426-443, 2010.

13. J.J. Lehot, E. Bonnefoy, J.P. Dalmas, S. Filley, O. Basttien and M. George, "Role of urapidil in the treatment of acute hypertension", Cah. Anesthesiol., vol. 43, pp. 67-76, 1995. 
14. J.H. Bremner, B. Coban, R. Griffith, K.M. Groenewoud and B.F. Yates, "Ligand design for $\alpha_{1}$ adrenoceptor subtype selective antagonists", Bioorg. Med. Chem., vol. 8, pp. 201-214, 2000.

15. T.E.T. Pompeu, F.R.S. Alves, C.D.M. Figueiredo, C.B. Antonio, V. Herzfeldt, B.C. Moura, S.M.K. Rates, E.J. Barreiroe, C.A.M. Fraga and F. Noël, "Synthesis and pharmacological evaluation of new $N$-phenylpiperazine derivatives designed as homologues of the antipsychotic lead compound LASSBio-579", Eur. J. Med. Chem., vol. 66, pp. 122-134, 2013.

16. V. Pittalà, M.A. Siracusa, M.N. Modica, L. Salerno, A. Pedretti, G. Vistoli, A. Cagnotto, T. Mennini and G. Romeo, "Synthesis and molecular modeling of $1 H$-pyrrolopyrimidine-2,4-dione derivatives as ligands for the $\alpha_{1}$ adrenoceptors", Bioorg. Med. Chem., vol. 19, pp. 5260-5276, 2011.

17. G. Romeo, L. Materia, M.N. Modica, V. Pittalà, L. Salerno, M.A. Siracusa, F. Manetti, M. Botta and K.P. Minneman, "Novel 4-phenylpiperidine-2,6-dione derivatives. Ligands for $\alpha_{1}$-adrenoceptor subtypes", Eur. J. Med. Chem.,vol. 46, pp. 2676-2690, 2011.

18. Bang-Andersen, T. Ruhland, M. Jørgensen, G. Smith, K. Frederiksen, K. Gjervig Jensen, H. Zhong, S. Møller Nielsen, S. Hogg, A. Mørk and T.B. Stensbøl, "Discovery of 1-[2-(2,4-dimethylphenylsulfanyl)phenyl]piperazine (Lu AA21004): a novel multimodal compound for the treatment of major depressive disorder", J. Med. Chem., vol. 54, pp. 3206-3221, 2011.

19. M. Baran, E. Kępczyńska, M. Żylewski, A. Siwek, M. Bednarski and M.T. Cegła, "Studies on novel pyridine and 2-pyridone derivatives of N-arylpiperazine as $\alpha$-adrenoceptor ligands", Med. Chem., vol. 10, pp. 144-153, 2014.

20. J.G. Lombardino and J.A. Lowe, "The role of the medicinal chemist in drug discovery--then and now", Nat. Rev. Drug Discov., vol. 3, pp. 853-862, 2004.

21. D.A. Smith, B.C. Jones and D.K. Walker, "Design of drugs involving the concepts and theories of drug metabolism and pharmacokinetics", Med. Res. Rev., vol. 16, pp. 243-266, 1996.

22. H. Van De Waterbeemd, D.A. Smith, K. Beaumont and D.K. Walker, "Property-based design: optimization of drug absorption and pharmacokinetics", J. Med. Chem., vol. 44, pp. 1313-1333, 2001.

23. T. Loftsson, Drug Stability for Pharmaceutical Scientists, Amsterdam: Academic Press, 2014.

24. S.R. Khan, M. Tawakkul, V.A. Sayeed, P. Faustino and M.A. Khan, "Stability characterization, kinetics and mechanism of degradation of dantrolene in aqueous solution: effect of $\mathrm{pH}$ and temperature", Pharmacol. Pharm., vol. 3, pp. 281-290, 2012.

25. M. Blessy, R.D. Patel, P.N. Prajapati and Y.K. Agrawal, "Development of forced degradation and stability indicating studies of drugs-A review", J. Pharm. Anal., vol. 4, pp. 159-165, 2014.

26. M.I. Walash and M.E.K. Wahba, "A validated liquid chromatographic method for the determination of fluphenazine hydrochloride in the presence of its degradation products: application to degradation kinetics", Anal. Meth., vol. 6, pp. 6727-6735, 2014.

27. M. Cegła, M. Baran, A. Czarny, M. Żylewski, J. Potaczek, J. Klenc and L.J. Strekowski, "The $-\mathrm{NH}-(\mathrm{C}=)-\mathrm{Br}$ functionality of heteroaromatic compounds as a synthon for fused dihydrooxazoles", J. Heterocyclic Chem., vol. 48, pp. 720-723, 2011.

28. J. Gajewska and S. Pietras, Physicochemical Guide, Warszawa: WNT, 1974. 